International Review of Research in Open and Distributed Learning

Volume 18, Number 1

February - 2017

\title{
Use of Social Media in Uncovering Information Services for People with Disabilities in China
}
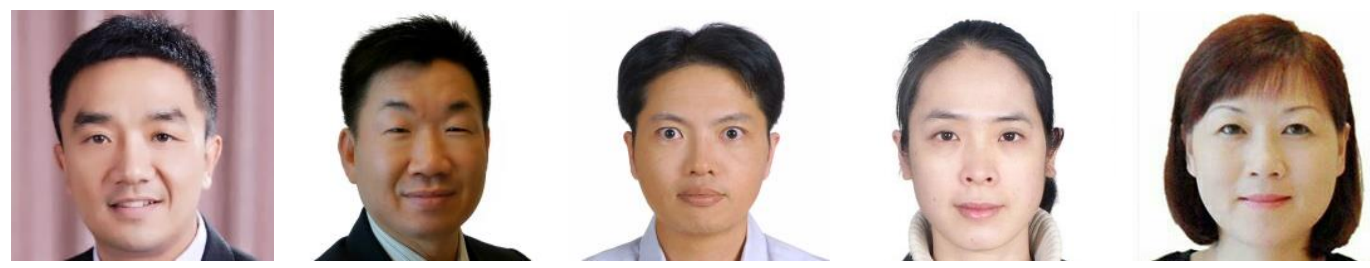

Wenke Wang1', Yen-Chun Jim Wu2,", Chih-Hung Yuan ${ }^{3}$, Hongxia Xiong1', and Wan-Ju Liu ${ }^{4}$

${ }^{1}$ Sichuan Normal University, China, ${ }^{2}$ National Taiwan Normal University, Taiwan, ${ }^{3}$ National Sun Yat-Sen University, Taiwan,

${ }^{4}$ National Taipei University, Taiwan

\begin{abstract}
The tangible and intangible needs of people with disabilities have been neglected in research agendas over the past decades, particularly in China. Bringing more benefits to people with disabilities and combining information delivery with Internet technology to improve their quality of life is impossible if their special needs are ignored. This study employed the crowdsourcing through social media method to investigate information needs of people who are disabled. The results indicate that using the popular social media platforms WeChat and QQ can be an effective means of reaching out to this group. Information needs can be mainly divided into internal and external needs. Leisure, tourism, and entertainment as well as assistive devices are major internal information needs, whereas work, entrepreneurship, and living services are the main external information needs.
\end{abstract}

Keywords: people with disabilities, feedback, crowdsourcing, information needs, social media, China

\section{Use of Social Media in Uncovering Information Services for People with Disabilities in China}

What can assist people with disabilities in improving their social inclusion and social situation? To answer this question, scholars have mainly focused on community participation (Milner \& Kelly, 2009), health

\footnotetext{
${ }^{*}$ Corresponding author
} 
(Tomlinson et al., 2009), welfare (Glendinning, 2008), assistive technology (Shi, 2015), information technology (García-Betances, Cabrera-Umpiérrez, Ottaviano, Pastorino, \& Arredondo, 2016), and communication (Domingo, 2012); few studies have examined the information needs of people with disabilities. Mitchell and Sloper (2002) indicated that providing information enables service users and their families to become more active participants in the society.

Demand for information services is considerably high among people with disabilities, with each person having a unique set of needs (Vicente \& López, 2010). However, their information needs are often overlooked by health planners and policy makers (Paudel, Dariang, Keeling, \& Mehata, 2016). Moreover, determining their needs and delivering suitable information to them is difficult because of the diversity of their disabilities. Critical discrepancies exist between the needs of people with disabilities and the services provided to them (Barrett, 2005; Ko \& McEnery, 2004). Bertot, Jaeger, and Hansen (2012) suggested that nonprofit organizations or governmental units must communicate effectively with people with disabilities to gain a clear understanding of their needs.

Rapid growth in the social acceptance of networking technology has led to an increase in social participation and has enabled new means of communication among people with disabilities. Although some people with disabilities do not have free access to a wide range of information because of their physical or mental disorder (Moisey, 2001; Myhill, 2002), many people with disabilities and their families want to receive relevant written information. Information workers generally do not have a clear understanding of the needs of people with disabilities, leading to a lack of user-centered designs (Carter \& Markel, 2001). Therefore, using a range of media to provide information on different levels is critical (Mitchell \& Sloper, 2002).

Most studies have determined the needs of specific groups through literature surveys, interviews, and focus group discussions (Barrett, 2005; Mitchell \& Sloper, 2002). The present study expanded the investigation to all types of disability groups. The rapid development of network technology has brought a new means for solving this problem: crowdsourcing (Ford, Richard, \& Ciuchta, 2015; Pitt-Catsouphes \& Cosner Berzin, 2015), which is a relatively new development in information outsourcing. It is a virtue of network platforms that cooperation can be extended worldwide through various virtual social groups. Any individual who is interested in or has some understanding about crowdsourcing can participate in crowdsourcing. In addition to reducing costs, crowdsourcing can bring answers that are more comprehensive, richer, and more creative compared with those derived from traditional investigation.

Two research questions were addressed in this study: (a) which platform do people with disabilities prefer to use, and (b) what types of service information do people with disabilities in China seek. These questions are critical because they can assist policy makers in both determining how to address the needs of people with disabilities and effectively reaching out to this special group. Therefore, in this study, the needs of various people with disabilities were investigated using the crowdsourcing method to improve the quality of online information services for people with disabilities.

The remainder of this article is structured as follows. Section 2 discusses research related to disabled information platforms and crowdsourcing, and Section 3 explains the research method. The research 
results are presented in Section 4, which is followed by a discussion in Section 5. Finally, Section 6 offers the conclusion of this research.

\section{Literature Review}

\section{Information Services Needs for People with Disabilities}

Developers and researchers are incorporating new paradigms into their personalized service tools to satisfy the needs and requirements of people with disabilities (García-Betances et al., 2016). Bień et al. (2013) explored unmet care needs in European countries and observed inequality in the distribution of social care services among countries. Mitchell and Sloper (2002) suggested that the family members of disabled children would like to receive customized guidance with comprehensive information. Matter et al. (2009) investigated the information needs of people with spinal cord injuries and found that the Internet was the most frequently used source for information on medical issues. Paudel et al. (2016) indicated that Nepal requires a community-based rehabilitation system and uniform database to assess social inclusion of people with disabilities. Ray and Ryder (2003) examined the needs of people with disabilities when planning to travel and found that online travel guides and word-of-mouth are critical information sources.

Ritchie and Blanck (2003) investigated 200 Center for Independent Living websites in the United States and found that these centres had already begun using network technology as a traditional service supplement. Johnson and Kent (2007) investigated the usability of web applications for elderly and disabled user. The results showed that designing the application module content to be more specific effectively improved the group work efficiency, accuracy, and user satisfaction of elderly adults and people with disabilities. Vicente and López (2010) found that, in 10 European countries, the information awareness of people with disabilities who use network technology is insufficient. Roberts, Crittenden, and Crittenden (2011) stressed that network learning platforms should meet the needs of students with disabilities to ensure that they can make full use of network information.

Currently, acceptance of social media and information and computer technology by the general public is increasing (Bertot et al., 2012; García-Betances et al., 2016), which can assist in reducing the information gap. Barrett (2005) used a questionnaire survey based on a review of the literature to explore the needs of people with disabilities. The results indicated a serious gap between their actual needs and the services they received. Luo, Zhang, and Liu (2015) suggested that organizations can establish community-based social media as a means of enhancing the relationship between them and their target groups. The link between social media and social issues is expected to become a popular topic in the near future (Zhang, Wang, de Pablos, Tang, \& Yan, 2015). Godfrey and Johnson (2009) reviewed the literature and summarized the information needs of elderly people, and found that networked interactive media systems are effective for providing advice as well as promoting and securing information for elderly people. However, risk, trust, and a friendly social interaction environment must be considered when developing social media platforms (Tang, Sung, \& Chang, 2015; Wang, Min, \& Han, 2016). 
$\mathrm{Xu}$, Kang, Song, and Clarke (2015) performed a survey on 39 top-ranked university libraries in China that used an official WeChat (a mobile communication service in China) account as a marketing tool. The results showed that the most frequently used functions were general social networking services, automatic reply, and interaction functions, whereas the more advanced functions, such as navigation services, assisted search, and self-services were in urgent need of improvement. Zheng and Yu (2016) applied the case study method and described how charity projects were implemented using Sina Weibo (a microblogging website) as a platform. They confirmed that social media plays an important role in the social transformation of China. Luo et al. (2015) conducted a questionnaire survey to examine how the establishment of a mobile phone brand group on social media affected loyalty. The results revealed that co-creation could enhance the relationships among consumers as well as the relationship between the customers and brand. Lien and Cao (2014) investigated the influence of psychological motivations on social media users' attitude, and to examine the effects of their attitude and trust on word-of-mouth. The results demonstrated that social activities, entertainment, information, and trust affect users' attitude. Users' attitude and trust also affect word-of-mouth reference. This implies that when policy-makers select communicating channels for people with disabilities, they should pay attention to their motivations and trust levels.

\section{Crowdsourcing}

The concept of crowdsourcing was first proposed by Howe (2006b), who defined crowdsourcing as "the act of a company or institution taking a function once performed by employees and outsourcing it to an undefined (and generally large) network of people in the form of an open call. This can take the form of peer-production (when the job is performed collaboratively), but is also often undertaken by sole individuals. The crucial prerequisite is the use of the open call format and the large network of potential laborers" (Howe, 2006a). Crowdsourced information is professional content provided by nonprofessionals, in which consumers are the content creators. On the basis of this definition, the concept of crowdsourcing has been further enriched and developed by other scholars.

Brabham (2008) indicated that crowdsourcing refers to enterprises that, through online publication, invite mass groups to participate in providing solutions to problems. This process is beneficial for enterprises, particularly because of the intellectual achievement of solving technical problems, obtaining new ideas online, overcoming distribution problems, and determining production patterns. Chanal and Caron-Fasan (2008) described crowdsourcing as open-innovation production by enterprises in which many external discrete resources are gathered through network devices. Such resources can be derived from individuals, teams, professionals, and amateurs. Studying why users contribute their knowledge to firm-hosted user communities, Jeppesen and Frederiksen (2006) indicated that the spiritual rewards derived from performing complex and creative crowdsourcing tasks are the intrinsic motives for users to become involved in crowdsourcing. Brabham (2008) argued that the main motivations for crowdsourcing among iStockphoto users are bonus incentives and improved abilities. 


\section{Methodology}

\section{Questionnaire Design}

The semi-structured questionnaires used in this study contained questions on the demographic information of participants, the online information platforms they wanted, and their needs for information services. To ensure the quality of the questionnaires, the following procedures were implemented. First, five experts (two professors, an associate professor, and two senior engineers) were invited to determine the classifications of online information platforms and open-ended questions about the unmet information services for the current and future needs. Finally, two rounds of pretests with 150 questionnaires for each round were carried out to determine the final form of the questionnaire.

\section{Participants and Procedures}

This study conducted a crowdsourcing survey to explore how people with disabilities in China find information services. We selected a sample of disabled Chinese people for following reasons. Although approximately $15 \%$ of the world's population has some form of disability, a survey conducted in China in 2006 revealed that 83 million (6.34\%) people living in China have at least one disability (Chen, Lin, Zhang, Song, \& Zheng, 2006; Paudel et al., 2016). According to People's Republic of China Disabled Citizens Protection Act, people with disabilities can be categorized into Vision, Hearing, Speaking, Physical, Mental, Intellectual, Multiple, and other disability categories. The rapid development of China's economy since the 1980 s has contributed substantially to improvements in the country's international status. As societies become more civilized and their economies are strengthened, people naturally pay closer attention to the various causes of people with disabilities. Social causes aimed at providing support for people with disabilities living in China have also become the focus of national leadership. In this development trend, the needs of Chinese people with disabilities are anticipated to exhibit potential opportunities to the practitioners and health planners.

The questionnaire survey was conducted anonymously through social media platforms, namely WeChat and QQ, in mid-2015. A total of 1,520 questionnaires were returned; after 492 invalid questionnaires were removed, 1,028 valid questionnaires remained (effective response rate, 67.23\%). Table 1 shows the distribution of the final sample: $58.56 \%$ of the participants were male, $69.56 \%$ were between 31 and 48 years old, 37.65\% had completed junior high school and 31.42\% had completed senior high school, 37.55\% lived in southwest China, $32.39 \%$ were unemployed, and $82.68 \%$ had a physical disability. 
Table 1

Sample Distribution

\begin{tabular}{|c|c|c|c|}
\hline Category & Classification & Times & Percentage \\
\hline \multirow[t]{2}{*}{ Sexual } & Male & 602 & $58.56 \%$ \\
\hline & Female & 426 & $41.44 \%$ \\
\hline \multirow[t]{4}{*}{ Age } & Below 30 & 165 & $16.05 \%$ \\
\hline & $31-42$ & 313 & $30.45 \%$ \\
\hline & $43-48$ & 402 & $39.11 \%$ \\
\hline & Above 49 & 148 & $14.40 \%$ \\
\hline \multirow{4}{*}{$\begin{array}{l}\text { Academic } \\
\text { background }\end{array}$} & Below primary school & 122 & $11.87 \%$ \\
\hline & Junior middle school & 387 & $37.65 \%$ \\
\hline & Senior middle school & 323 & $31.42 \%$ \\
\hline & Above junior college & 206 & $20.04 \%$ \\
\hline \multirow[t]{8}{*}{ Living area } & Southwest China & 386 & $37.55 \%$ \\
\hline & North China & 102 & $9.92 \%$ \\
\hline & East China & 89 & $8.66 \%$ \\
\hline & Northwest China & 65 & $6.32 \%$ \\
\hline & Central China region & 40 & $3.89 \%$ \\
\hline & Northeast China & 34 & $3 \cdot 31 \%$ \\
\hline & South China & 22 & $2.14 \%$ \\
\hline & $\mathrm{N} / \mathrm{A}$ & 190 & $18.48 \%$ \\
\hline \multirow[t]{8}{*}{ Job } & Unemployed & 333 & $32.39 \%$ \\
\hline & Freelancer & 176 & $17.12 \%$ \\
\hline & Retiree & 173 & $16.83 \%$ \\
\hline & Employee & 118 & $11.48 \%$ \\
\hline & $\begin{array}{l}\text { Self-employed } \\
\text { entrepreneurs }\end{array}$ & 90 & $8.75 \%$ \\
\hline & The government & 71 & $6.91 \%$ \\
\hline & Students & 26 & $2.53 \%$ \\
\hline & Other & 41 & $3.99 \%$ \\
\hline \multirow{6}{*}{$\begin{array}{l}\text { Main } \\
\text { classification of } \\
\text { the disabled }\end{array}$} & Limb & 850 & $82.68 \%$ \\
\hline & Vision & 63 & $6.13 \%$ \\
\hline & Hearing and language & 35 & $3.40 \%$ \\
\hline & Intellectual & 35 & $3.40 \%$ \\
\hline & Mental problem & 29 & $2.82 \%$ \\
\hline & Other & 16 & $1.56 \%$ \\
\hline \multirow[t]{3}{*}{ Disability rating } & First & 191 & $18.58 \%$ \\
\hline & Second & 301 & $29.28 \%$ \\
\hline & Third & 300 & $29.18 \%$ \\
\hline
\end{tabular}




\begin{tabular}{llll} 
& Fourth & 236 & $22.96 \%$ \\
\hline Earning & Under 500 & 228 & $22.18 \%$ \\
& $500-1000$ & 182 & $17.70 \%$ \\
& $1000-1500$ & 216 & $21.01 \%$ \\
& $1500-2000$ & 179 & $17.41 \%$ \\
& Above 2000 & 223 & $21.69 \%$ \\
\hline
\end{tabular}

\section{Encoding}

To avoid personal bias and classification errors during the coding and classification process, the authors trained two research assistants to assist with the encoding. One of the authors verified the consistency of the assigned codes. After encoding every 30 questionnaires, the team discussed how to compile and adjust the classification categories. To improve interrater reliability, the team members swapped their coding results with each other to ensure interrater reliability checks. Finally, a statistical analysis of the coding process yielded a kappa coefficient of 0.842 , showing that the encoding team achieved a high level of consistency. The information classification categories increased and evolved throughout the encoding process. The final products and services identified as relevant for the current and future needs of disabled users were divided into internal and external needs.

\section{Results}

\section{Network Platform}

The information that people with disabilities need is spread over a variety of online platforms, and the differences in information provided by different channels often result in a violation of the rights of people with disabilities. The survey results in Table 2 show that a plurality (29.70\%) of the respondents hoped that WeChat, more than any other network information platform, could provide advisory services for people with disabilities, followed by QQ (27.98\%) and other platforms. Furthermore, based on the current development of Internet information platforms, WeChat and QQ integrate more life services such as payment and transfer functions, group purchase services, and train ticket ordering services. Information services can be established more quickly to achieve integration with existing services on WeChat and QQ; forming such a network provides a service system for people with disabilities, bringing them a more ideal information service. In addition to those who hoped for WeChat and QQ to develop services for people with disabilities, 24.06\% of the respondents hoped that Web pages could be provided for people with disabilities; such pages are the mainstream platform for disseminating information over networks.

\section{Information Service Requirements}

Table 3 displays the internal information needs of people with disabilities. Leisure, tourism, and entertainment information were the most pertinent needs, accounting for $13.55 \%$ of all needs. From the 
perspective of future needs, leisure, tourism, and entertainment continues to be the greatest need, accounting for $\mathbf{1 4 . 0 5 \%}$ of all needs. Leisure travel barriers include the intrinsic nature of disabilities, environmental constraints, and interaction barriers (Lee, Agarwal, \& Kim, 2012). In 2013, the General Office of the State Council issued the Outline for National Tourism and Leisure (2013-2020). The document strengthened the no-barrier construction of tourism leisure sites for people with disabilities to improve the quality for people with disabilities of leisure travel services provided by public services and leisure environments. The promulgation of the outline not only ensures that leisure travel markets recognize this special consumer group, but also facilitates increasing the demand among people with disabilities for leisure and tourism activities.

Table 2

Information Platform Preference

\begin{tabular}{lcc}
\hline Platform & Times & Percentage \\
\hline WeChat & 621 & $29.70 \%$ \\
QQ & 585 & $27.98 \%$ \\
Web pages & 503 & $24.06 \%$ \\
Apps & 229 & $10.95 \%$ \\
Weibo & 141 & $6.74 \%$ \\
Other & 12 & $0.57 \%$ \\
\hline Total & 2091 & $100 \%$ \\
\hline
\end{tabular}

Table 3

Internal Demand

\begin{tabular}{|c|c|c|c|c|c|c|}
\hline \multirow{3}{*}{$\begin{array}{l}\text { Classification } \\
\text { Leisure, } \\
\text { tourism and } \\
\text { entertainmen }\end{array}$} & \multirow{2}{*}{$\begin{array}{l}\text { Content } \\
\text { Group and package } \\
\text { tour }\end{array}$} & \multicolumn{2}{|c|}{ Existing demand } & \multicolumn{2}{|c|}{ Future demand } & \multirow{2}{*}{$\begin{array}{c}\text { Total } \\
287(13.75 \%)\end{array}$} \\
\hline & & 110 & $170(13.55 \%)$ & 55 & $117(14.05 \%)$ & \\
\hline & Barrier-free tourism & 40 & & 41 & & \\
\hline $\mathrm{t}$ & Travel consulting & 14 & & 6 & & \\
\hline \multirow{7}{*}{$\begin{array}{l}\text { Assistive } \\
\text { Devices }\end{array}$} & Travel aboard & 1 & & 4 & & \\
\hline & Film and television & 5 & & 11 & & \\
\hline & Assistive devices & 31 & $129(10.28 \%)$ & 50 & $79(9.48 \%)$ & 208(9.96\%) \\
\hline & Motion-aid Device & 47 & & 5 & & \\
\hline & Life assistive devices & 30 & & 7 & & \\
\hline & $\begin{array}{l}\text { Orthodontic } \\
\text { appliance }\end{array}$ & 4 & & 1 & & \\
\hline & Rehabilitation aids & 1 & & 3 & & \\
\hline
\end{tabular}




\begin{tabular}{|c|c|c|c|c|c|c|}
\hline & $\begin{array}{l}\text { Private mobile } \\
\text { phone and computer }\end{array}$ & 16 & & 13 & & \\
\hline \multirow[t]{5}{*}{ Health care } & Medical & 4 & $92(7.33 \%)$ & 9 & $44(5.28 \%)$ & $136(6.51 \%)$ \\
\hline & Recovery & 43 & & 15 & & \\
\hline & $\begin{array}{l}\text { Psychological } \\
\text { counseling }\end{array}$ & 10 & & 5 & & \\
\hline & Medical treatment & 9 & & 7 & & \\
\hline & Health & 26 & & 8 & & \\
\hline \multirow{2}{*}{$\begin{array}{l}\text { Electronic } \\
\text { Commerce }\end{array}$} & $\begin{array}{l}\text { Electronic } \\
\text { commerce }\end{array}$ & 23 & $27(2.15 \%)$ & 18 & $23(2.76 \%)$ & $50(2.39 \%)$ \\
\hline & Finance & 4 & & 5 & & \\
\hline Resource & Resource integration & 1 & $1(0.08 \%)$ & 6 & $6(0.72 \%)$ & $7(0.34 \%)$ \\
\hline
\end{tabular}

The need for assistive devices was ranked second, accounting for $10.28 \%$ and $9.48 \%$ of current and future needs, respectively. From the perspective of the psychological aspects of disability, people with disabilities may be said to want to live a normal life as able-bodied people. Assistive devices can improve the work efficiency of people with disabilities, and such devices are inseparable from the auxiliary tools that assist them in life and work. Assistive devices "help me get on in life. We all have different ways of getting on in life. This is my way" (Gibson, Carnevale, \& King, 2012, p. 1894). Currently, the design and manufacture of appliances for people with disabilities in China lags far behind that in developed countries. People with disabilities have a relatively low income level. Therefore, among the various types of auxiliary equipment supplied in China, people with disabilities focus more on mobility aids. Some advanced auxiliary tools remain unaffordable for most people with disabilities living in China, despite their eagerness for such devices. Therefore, providers of information on auxiliary appliances should continue to pay close attention to the needs of people with disabilities.

The need for relevant medical information among people with disabilities exhibited a downward trend (7.33\% to 5.28\%), indicating an optimistic attitude regarding the future of China's medical security system for people with disabilities. The need for rehabilitation information accounted for a high proportion of their information needs, indicating a psychological state in which they are eager to return to normal life. Although the proportion of medical information needs has declined, as a basic type of information for people with disabilities, this type of information need is closely related to their daily living. Moreover, it remains a critical part of information platform content that cannot be ignored. The e-commerce and resource integration information needs of people with disabilities were ranked low, with both accounting for less than $5 \%$ of their information needs.

Regarding external information (Table 4), approximately $24.86 \%$ of information needs are related to work and entrepreneurship advisory services. According to Table 1, most of the respondents were unemployed or worked in freelance positions, and, compared with other social groups, faced more severe employment problems. Paid work is a core production activity that has a marked impact on quality of life (Fekete, Wahrendorf, Reinhardt, Post, \& Siegrist, 2014). More than half of the families of people with disabilities 
have a per capita monthly income below $1,500 \mathrm{RMB}$, which also reflects the general problem of the low income level of people with disabilities. Although China has issued relevant policies and regulations to protect people with disabilities in their employment, the employment conditions for people with disabilities remain the main problem affecting social justice; people with disabilities in China desperately require work and entrepreneurship class information services.

The need for socializing information accounted for $14.80 \%$ of all information needs. People with disabilities in China might be hindered not by physical disabilities but by psychological barriers. The collective attitude of people living with people with disabilities and the attitudes of other social groups toward people with disabilities tend to exacerbate the feeling of loneliness experienced by people with disabilities. Exchange information services for people with disabilities provide more chances for communication and opportunities for self-expression, enabling self-improvement, and providing a deep sense of relief. Therefore, WeChat and QQ, the two largest chat-based social media platforms in China, demonstrate the highest potential to become network information platforms that provide consultation services for people with disabilities.

Table 4

External Demand

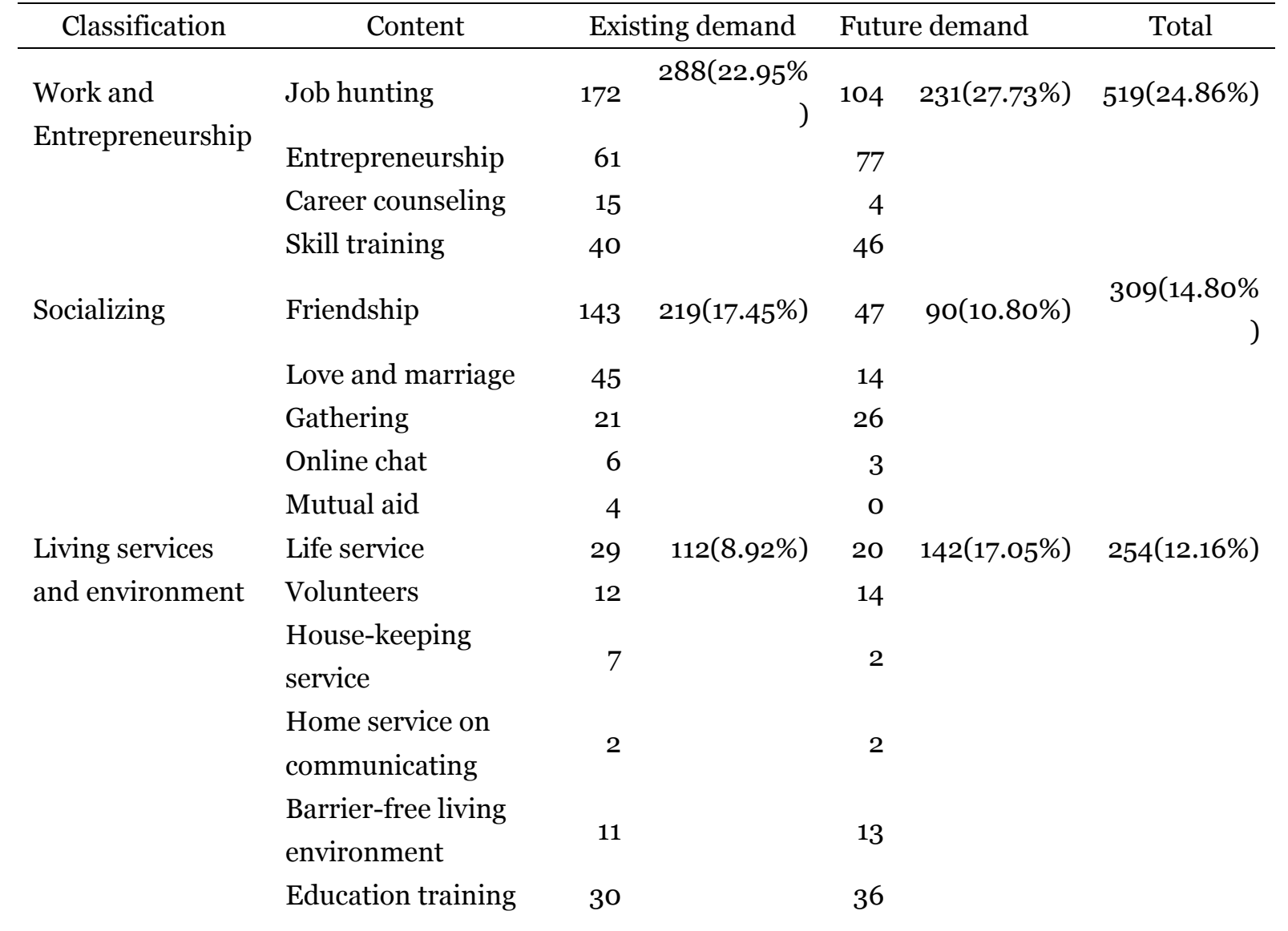




\begin{tabular}{|c|c|c|c|c|c|c|}
\hline & Elder care & 10 & & 28 & & \\
\hline & Consulting & 10 & & 18 & & \\
\hline & Shuttle service & 1 & & 9 & & \\
\hline \multirow[t]{6}{*}{ Information news } & General information & 56 & $161(12.83 \%)$ & 25 & $65(7.80 \%)$ & $226(10.82 \%$ \\
\hline & Healthy information & 5 & & 3 & & \\
\hline & $\begin{array}{l}\text { Legal policy } \\
\text { information }\end{array}$ & 68 & & 23 & & \\
\hline & $\begin{array}{l}\text { Related information } \\
\text { about the disabled }\end{array}$ & 24 & & 7 & & \\
\hline & News & 8 & & 7 & & \\
\hline & General information & 56 & $161(12.83 \%)$ & 25 & $65(7.80 \%)$ & $226(10.82 \%$ \\
\hline \multirow{4}{*}{$\begin{array}{l}\text { Social inclusion } \\
\text { and policy }\end{array}$} & Be treated fairly & 18 & $56(4.46 \%)$ & 21 & $36(4.32 \%)$ & $92(4.41 \%)$ \\
\hline & Living security & 7 & & 5 & & \\
\hline & Policies & 11 & & 10 & & \\
\hline & Assistant or discount & 20 & & $\mathrm{O}$ & & \\
\hline
\end{tabular}

The living services and the environment accounted for $8.92 \%$ of current information needs. The environment can encourage people with disabilities to participate in and integrate themselves into their culture, economy, and society (Domingo, 2012). Because some people with disabilities have physical disabilities and must also overcome psychological obstacles, they cannot leave their homes for daily life activities. Currently, the construction of obstacle-free environments remains in the initial stage in China. Many businesses or life service institutions do not provide specialized services for people with disabilities for the sake of their own interests. A consultation service platform for the disabled can bring convenience for most people with disabilities, enabling them to overcome obstacles in their daily life.

According to the survey results, people with disabilities focus primarily on work and entrepreneurship information. Because of the importance of such information, it affects the basic life quality and living environment of people with disabilities. Thus, this type of information will always be the main content to consider when constructing an information platform because it will affect the lives of people with disabilities. Furthermore, attention should be given to enhancing education and training information to meet the needs of people with disabilities. People with disabilities have realized that network information is not only for their temporary needs; they also fully use diverse information networks and exploit their convenience to strengthen their personal knowledge. Advisory service platforms for people with disabilities can be considered critical resources for establishing sustainable development. This also indicates that attention should be given to the sustainability of such information and the timeliness of its value for people with disabilities. 


\section{Discussion}

The first research question asks, "Which platform do people with disabilities prefer to use?" Our results reveal that Wechat and QQ are the most favorable network information platform. Social media have become crucial platforms for information exchange, where people with disabilities can easily acquire information and health planners can interact with and listen to their target groups (Raghavendra, Newman, Grace, \& Wood, 2015). Such platforms are for placing collaborative learning, social learning, and value cocreation practices between organizations and their customers (Luo et al., 2015; Zhang, Gao, et al., 2015; Zhang, Wang, et al., 2015). Our results reveal that WeChat and QQ are the most favorable network information platforms. In addition, both WeChat and QQ have voice message functionality, which could meet the special needs of people with disabilities. Guo, Bricout, and Huang (2005) indicated that the Internet can effectively reduce existing social barriers in social and physical environment for people with disabilities. Research has shown that social media platforms such as WeChat, Twitter, and Facebook are developing rapidly in the contexts of interpersonal communication, news and information dissemination, education, and other fields (Chen \& Bryer, 2012; Gikas \& Grant, 2013). People with disabilities can access information they are interested in through operating a user interface. This suggests that policy makers can set an information community on social media as a means to help people with disabilities.

The second research question states, "What types of service information do people with disabilities in China seek?" Our results suggest that the needs of information can be divided into internal demand and external demand. Regarding the internal needs of people with disabilities, leisure, tourism, and entertainment; assistive devices; and medical service were ranked as the top three needs and are thus worthy of attention. A report by the China Disabled Persons' Federation estimated that $60 \%$ of people with disabilities in China have leisure travel needs (China Disabled Persons' Federation, 2003). Bi, Card, and Cole (2007), indicating that China's tourism market for people with disabilities has considerable potential for growth. To satisfy this need, professional services and accurate information must be provided (Darcy, 1998). Ray and Ryder (2003) also stressed that online travel guides serve as the most critical factor. Therefore, understanding leisure, tourism, and environmental needs for people with disabilities can improve tourism participation (Packer, McKercher, \& Yau, 2007).

The lack of mobility is one of the major problems that people with disabilities face (Gibson et al., 2012). Limited abilities and a limited range of motion cause people with disabilities to experience negative emotions, which then affect their spiritual and cultural life. Solving activity-constrained problems for people with disabilities is crucial in meeting their needs. Improving activities for people with disabilities mainly relies on auxiliary tools (Yang, 2012). Therefore, the importance of auxiliary tool information for people with disabilities cannot be ignored.

Medical information is a critical part of life and is closely connected with ensuring that people with disabilities lead a healthy life. Physical health is the most important factor to measure when examining the life quality of people with disabilities (Xu, Wang, Xiang, \& Hu, 2005). Our results accord with those of O’Regan and Drummond (2008), who revealed the importance of relevant medical information for people 
with disabilities. Rehabilitation for people with disabilities is another main requirement that must be addressed in China (Stratford \& Ng, 2000). The present study suggests that basic medical information should be provided to people with disabilities and continually updated to help them improve their life quality.

From the perspective of external information needs, both present and future, the two major information types sought by people with disabilities in China are: (a) work and entrepreneurial information and (b) life services and environmental information. Because work is the most crucial source of income for people with disabilities, it is fundamental to their basic survival needs (Fekete et al., 2014). The need for life services and environmental information reflects the pursuit of independence in the daily lives of people with disabilities. They hope that society can create an environment in which they can live like able-bodied people rather than simply receive relief through social welfare systems (Lan, 2008). McLoughlin, Zhou, and Clark (2005) also showed that the modernization of special education services (information on life services and the environment) is crucial to ensuring that people with disabilities can develop their abilities.

When information service platforms are constructed for people with disabilities, the services should meet the peoples' needs and be updated regularly to ensure sustainability (Carter \& Markel, 2001; Myhill, 2002). In other words, sustainability should be a critical consideration when constructing service platforms for people with disabilities.

\section{Implications for Practice}

The findings of this paper have several implications for policy makers and practitioners interested in the needs of people with disabilities and advocacy for them. First, the most valuable information for people with disabilities is work-related information for the present and for the future. Employers and policymakers should set up an online zone containing job searching information for people with disabilities. Tailored to the needs of people with disabilities, job vacancies can be published proactively through social media. Furthermore, there is also a great demand from people with disabilities for work-related training, skills, starting a business, and education. Therefore, an integrated informative platform can be established to provide information on employment for people with disabilities, diverse vocational training, and courses. This platform can also be linked to job centres and vocational training institutes or universities in order to provide distance-learning and technological education to people with disabilities. In China, people with disabilities are scattered across the country and do not have easy mobility, which makes distance learning an effective solution. Diversified courses should be designed to fit these specific needs. Combining the knowledge and modern technology with effective vocational training and placement, assistance can be provided to people with disabilities in finding employment, which in turn, will enable them to become economically independent and participate in social activities. Mobile learning technology can indeed fulfill the needs of special education and increase learners' interests in learning and participation (FernándezLópez, Rodríguez-Fórtiz, Rodríguez-Almendros, \& Martínez-Segura, 2013).

Second, people with disabilities mostly engage in their daily activities within their residence; therefore, information on social and recreational activities is an urgent need for them. In the future, policymakers 
should provide a leisure travel environment that is accessible to users with disabilities. They should also plan for a comprehensive information system, allowing practitioners or people with disabilities to look up information. Practitioners can also launch tours and activity packages of diverse recreational travel that are suitable for people with disabilities, in order to satisfy their social, recreational, and developmental needs. Moreover, due to the additional difficulties experienced by people with physical or psychological disabilities in meeting people romantically, one recommendation is to set up friend groups on social media for this population to look for partners.

Third, since people with disabilities are more vulnerable to encounter limitations in employment, education, transport, communications, housing, and other areas, government authorities should strengthen their legal consultation services to help prevent or resolve such issues. People with disabilities should be provided equal opportunities to ensure that they can benefit from the projects, services, and activities organized by

the government. Fourth, the government must possess the ability to effective communicate with people with disabilities. The current information system only relies on certain forms of senses and abilities, and operations compatible with multiple forms are rare. Social media can convey words, graphics, documents, sounds, and videos, and it also offers opportunities for public and private interactions, enhancing the ability to exchange. Nonetheless, the attitude and trust of people with disabilities remain the determining factors for the effectiveness of informational communication channels using the word-of-mouth approach in social media (Lien \& Cao, 2014). Lastly, future policymakers can define policy priorities based on the urgency and importance of existing and future needs in order to gradually build a website of information for people with disabilities on social media.

\section{Limitations and Future Research Directions}

First, in this study, we adopted a crowdsourcing research method. However, in reality, many people with disabilities have had no contact with network information technology. Therefore, the adopted methods have some limitations. Second, the only crowdsourcing platforms we distributed the questionnaire through were WeChat and QQ, which reduced the size and generalizability of our sample. Finally, we obtained only 1,028 effective samples. Narrowing the scope of the investigation may have influenced the accuracy of our analysis results.

On the basis of this paper, future research will be devoted to gaining a deeper understanding of the information needs of people with different types of disabilities. Differences in the living environments and physiological states of different groups of people with disabilities show that their information needs vary. The sample target should be extended beyond disabled groups with physical disabilities, and the investigation should not be confined to crowdsourcing. Through a field investigation, we could communicate with people with disabilities face to face, and other methods may reveal more information about their needs. In addition, regarding information service platforms for people with disabilities, their content needs must be combined with developing relevant Web technologies. From professional Web development and technical perspectives, the needs of people with disabilities must be classified in a more detailed manner to ensure that they are provided with professional, specialized, and personalized disabled 
information platforms that satisfy their needs.

\section{Conclusion}

The crowdsourcing method was adopted to study the information needs of people with disabilities. Our results show that people with disabilities hope to be provided with network information platforms such as WeChat and QQ, which can be utilized as information services, because these platforms accommodate a wide range of users and feature a more humanized research and development design; moreover, they are at a mature stage of development. The information needs of people with disabilities can mainly be divided into internal and external needs. The major internal needs are leisure, tourism, and entertainment as well as assistive devices. The major external needs are mainly work and entrepreneurship and life service needs.

\section{Acknowledgement}

Social Science Planning Project in 12th Five-Year of Sichuan Province (No. SC15Bo71) \& Ministry of Science \& Technology, Taiwan.

\section{References}

Barrett, J. (2005). Support and information needs of older and disabled older people in the UK. Applied Ergonomics, 36(2), 177-183.

Bertot, J. C., Jaeger, P. T., \& Hansen, D. (2012). The impact of polices on government social media usage: Issues, challenges, and recommendations. Government Information Quarterly, 29(1), 30-40.

Bi, Y., Card, J. A., \& Cole, S. T. (2007). Accessibility and attitudinal barriers encountered by Chinese travellers with physical disabilities. International Journal of Tourism Research, 9(3), 205-216.

Bień, B., McKee, K. J., Döhner, H., Triantafillou, J., Lamura, G., Doroszkiewicz, H., . . Kofahl, C. (2013). Disabled older people's use of health and social care services and their unmet care needs in six European countries. European Journal of Public Health, 23(6), 1032-1038.

Brabham, D. C. (2008). Crowdsourcing as a model for problem solving: An introduction and cases. Convergence: The International Journal of Research into New Media Technologies, 14(1), 75-90.

Carter, J., \& Markel, M. (2001). Web accessibility for people with disabilities: An introduction for web developers. IEEE Transactions on Professional Communication, 44(4), 225-233.

Chanal, V., \& Caron-Fasan, M.-L. (2008, 2008-05-29). How to invent a new business model based on crowdsourcing: The Crowdspirit $\AA$ case. Paper presented at the Conférence de l'Association Internationale de Management Stratégique, Sophia-Antipolis, France. 
Chen, B., \& Bryer, T. (2012). Investigating instructional strategies for using social media in formal and informal learning. International Review of Research in Open and Distance Learning, 13(1), 18.

Chen, G., Lin, Y., Zhang, L., Song, X., \& Zheng, X. (2006). Livelihood situation of disabled population in China. Beijing: The State Council Information Office of the Peolple's Republic of China.

China Disabled Persons' Federation. (2003). The disability statistics in China. Workshop on improving disability data for policy use. Retrieved from http://www.worldenable.net/escapstats/paperchina3.htm

Darcy, S. (1998). Anxiety to access: Tourism patterns and experiences of New South Wales people with a physical disability. Sydney: Tourism New South Wales.

Domingo, M. C. (2012). An overview of the Internet of Things for people with disabilities. Journal of Network and Computer Applications, 35(2), 584-596.

Fekete, C., Wahrendorf, M., Reinhardt, J., Post, M., \& Siegrist, J. (2014). Work stress and quality of life in persons with disabilities from four European countries: The case of spinal cord injury. Quality of Life Research, 23(5), 1661-1671.

Fernández-López, Á., Rodríguez-Fórtiz, M. J., Rodríguez-Almendros, M. L., \& Martínez-Segura, M. J. (2013). Mobile learning technology based on iOS devices to support students with special education needs. Computers \& Education, 61, 77-90.

Ford, R. C., Richard, B., \& Ciuchta, M. P. (2015). Crowdsourcing: A new way of employing nonemployees? Business Horizons, 58(4), 377-388.

García-Betances, R. I., Cabrera-Umpiérrez, M. F., Ottaviano, M., Pastorino, M., \& Arredondo, M. T. (2016). Parametric cognitive modeling of information and computer technology usage by people with aging- and disability-derived functional impairments. Sensors (Basel, Switzerland), 16(2), 266.

Gibson, B. E., Carnevale, F. A., \& King, G. (2012). "This is my way": Reimagining disability, in/dependence and interconnectedness of persons and assistive technologies. Disability \& Rehabilitation, 34(22), 1894-1899.

Gikas, J., \& Grant, M. M. (2013). Mobile computing devices in higher education: Student perspectives on learning with cellphones, smartphones \&amp; social media. The Internet and Higher Education, 19, 18-26.

Glendinning, C. (2008). Increasing choice and control for older and disabled people: A critical review of new developments in England. Social Policy \& Administration, 42(5), 451-469.

Godfrey, M., \& Johnson, O. (2009). Digital circles of support: Meeting the information needs of older people. Computers in Human Behavior, 25(3), 633-642. 
Guo, B., Bricout, J. C., \& Huang, J. (2005). A common open space or a digital divide? A social model perspective on the online disability community in China. Disability \& Society, 2O(1), 49-66.

Howe, J. (2006a). Crowdsourcing: A Definition. Retrieved from http://crowdsourcing.typepad.com/cs/2006/06/crowdsourcing_a.html

Howe, J. (2006b). Gannett to crowdsource news. Retrieved from http://archive.wired.com/software/webservices/news/2006/11/72067?currentPage=all

Jeppesen, L. B., \& Frederiksen, L. (2006). Why do users contribute to firm-hosted user communities? The case of computer-controlled music instruments. Organization Science, 17(1), 45-63.

Johnson, R., \& Kent, S. (2007). Designing universal access: Web-applications for the elderly and disabled. Cognition, Technology \& Work, 9(4), 209-218.

Ko, B., \& McEnery, G. (2004). The needs of physically disabled young people during transition to adult services. Child: Care, Health and Development, 3o(4), 317-323.

Lan, H. (2008). Reconstruction of social welfare system of disabled persons in China-from the relief mode to the "obstacle" model. Tianjin: Nankai University. (in Chinese)

Lee, B. K., Agarwal, S., \& Kim, H. J. (2012). Influences of travel constraints on the people with disabilities' intention to travel: An application of Seligman's helplessness theory. Tourism Management, 33(3), 569-579.

Lien, C. H., \& Cao, Y. (2014). Examining WeChat users' motivations, trust, attitudes, and positive wordof-mouth: Evidence from China. Computers in Human Behavior, 41, 104-111.

Luo, N., Zhang, M., \& Liu, W. (2015). The effects of value co-creation practices on building harmonious brand community and achieving brand loyalty on social media in China. Computers in Human Behavior, 48, 492-499.

Matter, B., Feinberg, M., Schomer, K., Harniss, M., Brown, P., \& Johnson, K. (2009). Information needs of people with spinal cord injuries. The Journal of Spinal Cord Medicine, 32(5), 545-554.

McLoughlin, C. S., Zhou, Z., \& Clark, E. (2005). Reflections on the development and status of contemporary special education services in China. Psychology in the Schools, 42(3), 273-283.

Milner, P., \& Kelly, B. (2009). Community participation and inclusion: people with disabilities defining their place. Disability \& Society, 24(1), 47-62.

Mitchell, W., \& Sloper, P. (2002). Information that informs rather than alienates families with disabled children: Developing a model of good practice. Health \& Social Care in the Community, 1O(2), 74-81. 
Moisey, S. D. (2001). A virtual community for adults with developmental disabilities and their families. The International Review of Research in Open and Distributed Learning, 2(1).

Myhill, C. E. (2002). ICT for access to information services for disabled people: An overview of projects and services at Gateshead Libraries Service. Program: Electronic Library and Information Systems, $36(3), 176-181$.

O'Regan, P., \& Drummond, E. (2008). Cancer information needs of people with intellectual disability: A review of the literature. European Journal of Oncology Nursing, 12(2), 142-147.

Packer, T. L., McKercher, B., \& Yau, M. K. (2007). Understanding the complex interplay between tourism, disability and environmental contexts. Disability \& Rehabilitation, 29(4), 281-292.

Paudel, Y. R., Dariang, M., Keeling, S. J., \& Mehata, S. (2016). Addressing the needs of people with disability in Nepal: The urgent need. Disability and Health Journal, 9(2), 186-188.

Pitt-Catsouphes, M., \& Cosner Berzin, S. (2015). Teaching note-Incorporating social innovation content into macro social work education. Journal of Social Work Education, 51(2), 407-416.

Raghavendra, P., Newman, L., Grace, E., \& Wood, D. (2015). Enhancing social participation in young people with communication disabilities living in rural Australia: Outcomes of a home-based intervention for using social media. Disability and Rehabilitation, 37(17), 1576-1590.

Ray, N. M., \& Ryder, M. E. (2003). "Ebilities” tourism: An exploratory discussion of the travel needs and motivations of the mobility-disabled1. Tourism Management, 24(1), 57-72.

Ritchie, H., \& Blanck, P. (2003). The promise of the Internet for disability: A study of on-line services and web site accessibility at Centers for Independent Living. Behavioral Sciences \& the Law, 21(1), 5-26.

Roberts, J. B., Crittenden, L. A., \& Crittenden, J. C. (2011). Students with disabilities and online learning: A cross-institutional study of perceived satisfaction with accessibility compliance and services. The Internet and Higher Education, 14(4), 242-250.

Shi, W. (2015). A survey on assistive technologies for elderly and disabled people. Journal of Mechatronics, 3(2), 121-125.

Stratford, B., \& Ng, H. (2000). People with disabilities in China: Changing outlook- new solutionsgrowing problems. International Journal of Disability, Development and Education, 47(1), 7-14.

Tang, J. T., Sung, Y.-T., \& Chang, K.-E. (2015). Action research on the development of Chinese communication in a virtual community. Computer Assisted Language Learning, 1-26.

Tomlinson, M., Swartz, L., Officer, A., Chan, K. Y., Rudan, I., \& Saxena, S. (2009). Research priorities for health of people with disabilities: An expert opinion exercise. The Lancet, 374(9704), 1857-1862. 
Vicente, M. R., \& López, A. J. (2010). A multidimensional analysis of the disability digital divide: Some evidence for internet use. Information Society, 26(1), 48-64.

Wang, Y., Min, Q., \& Han, S. (2016). Understanding the effects of trust and risk on individual behavior toward social media platforms: A meta-analysis of the empirical evidence. Computers in Human Behavior, 56, 34-44.

Xu, J., Kang, Q., Song, Z., \& Clarke, C. P. (2015). Applications of mobile social media: WeChat among academic Libraries in China. The Journal of Academic Librarianship, 41(1), 21-30.

Xu, J., Wang, M., Xiang, Y., \& Hu, X. (2005). Quality of life for people with intellectual disabilities in China: A cross-culture perspectives study. Journal of Intellectual Disability Research, 49(10), 745749 .

Yang, J. (2012). Study on the demand and effect of the combination of assistive devices for the disabled in Shanghai. Shanghai: Fudan University. (In Chinese)

Zhang, X., Gao, Y., Yan, X., de Pablos, P. O., Sun, Y., \& Cao, X. (2015). From e-learning to social-learning: Mapping development of studies on social media-supported knowledge management. Computers in Human Behavior, 51, Part B, 803-811.

Zhang, X., Wang, W., de Pablos, P. O., Tang, J., \& Yan, X. (2015). Mapping development of social media research through different disciplines: Collaborative learning in management and computer science. Computers in Human Behavior, 51, Part B, 1142-1153.

Zheng, Y., \& Yu, A. (2016). Affordances of social media in collective action: The case of free lunch for children in China. Information Systems Journal, 26(3), 289-313.

\section{Athabasca University}

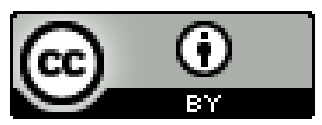

